\title{
PENSAR O GESTO DANÇADO ENTREVISTA COM CHRISTINE ROQUET
}

\author{
Guilherme Hinz \\ Mestrando em Dança pela Universidade Paris 8 \\ hinz.guilherme@gmail.com
}

Resumo

Após uma formação em análise do movimento com Odile Rouquet e em seguida com Hubert Godard, no departamento de Dança da Universidade Paris 8, Christine Roquet defende em 2002 seu doutorado intitulado "La scène amoureuse en danse: codes, modes et normes de l'intercorporéité dans le duo chorégraphique" [A cena amorosa na dança: códigos, modos e normas da intercorporeidade no duo coreográfico]. Desde 2003, ela é professora de análise do movimento nesse mesmo departamento e é responsável pelo curso de graduação Arts du spectacle chorégraphique. Nesta entrevista, realizada em janeiro de 2017 em Fontenay-sous-Bois (França), Christine Roquet contextualiza em um primeiro momento como a análise do movimento - proveniente do campo da Dança - se desenvolveu na França e, na segunda parte, a discussão toma como eixo central a abordagem particular do departamento de Dança da Universidade Paris 8. A problemática da definição de um campo de estudo; o parentesco entre práticas somáticas, notação do movimento e aulas de dança e a especificidade das teorias desenvolvidas por Michel Bernard e Hubert Godard são alguns dos temas que atravessam essa conversa entre uma professora e um aluno que inicia seus estudos nesta área.

Análise Do Movimento. Dança. Departamento Dança da Universidade Paris 8. Gesto Expressivo.
Abstract

Having trained in movement analysis with Odile Rouquet and then with Hubert Godard in the Dance department of the University Paris 8, Christine Roquet completed in 2002 her doctorate entitled "La scène amoureuse en danse: codes, modes et normes de l'intercorporéité dans le duo chorégraphique" [The love scene in dance: codes, modes and standards of intercorporeality in the choreographic duo]. Since 2003 , she is a professor of movement analysis in the same department, where she is also responsible for the bachelor's degree course Arts du spectacle chorégraphique. In this interview, conducted in January 2017 in Fontenay-sousBois (France), Christine Roquet first explains how the movement analysis - originating from the field of dance - has developed in France and then the discussion gives a main place to the approach of the Dance department of the University Paris 8 . The problem of defining a field of study; the kinship between somatic practices, notation of movement and dance classes; the specificity of the theories developed by Michel Bernard and Hubert Godard are themes that run through this conversation between a professor and a student who begins his studies in this area.

Keywords

Movement Analysis. Dance. Dance Department of the University Paris 8. Expressive Gesture. 
Guilherme Hinz - Minha ideia é começar por um panorama histórico a fim de pensar como a análise do movimento se desenvolveu na França e, em um segundo momento, reorientar o foco da conversa para a abordagem específica do departamento de Dança ${ }^{1}$ da Universidade Paris 8, departamento no qual você desenvolve essa linha de pesquisa. Então, minha primeira pergunta seria: na sua opinião, como foi construído o campo da análise do movimento?

Christine Roquet - O primeiro elemento a considerar é que o que vai ser dito aqui diz respeito à análise do movimento que se desenvolve na França. Trata-se de uma área do conhecimento relativamente nova que inclui o que é denominado pelo Ministério da Cultura como "Análise funcional do corpo no movimento dançado" (AFCMD). A AFCMD foi criada nos anos 19801990, de um lado pelos cursos privados de Odile Rouquet ${ }^{3}$ em Paris e, de outro, mais ou menos nessa mesma época, pelo trabalho de

\footnotetext{
1 Criado em 1989 pelo filósofo e professor Michel Bernard e chefiado em seguida por este e por Hubert Godard, o departamento de Dança da Universidade Paris 8 é composto atualmente por seis pesquisadoras permanentes - Isabelle Ginot, Mahalia Lassibille, Isabelle Launay, Sylviane Pagès, Julie Perrin e Christine Roquet - além de contar com pesquisadores e artistas associados (Laurent Pichaud), professores estrangeiros, artistas e pedagogos convidados. http://www. danse.univ-paris8.fr/
}

2 Analyse fonctionnelle du corps dans le mouvement dansé. Os conhecimentos ensinados nesta disciplina são baseados em estudos de cinesiologia, anatomia, fisiologia e neurologia. A AFCMD foi institucionalizada em 1990 pelo Ministério da Cultura, tornando-se uma disciplina obrigatória na formação de professores de dança na França.

3 Coreógrafa e bailarina, Odile Rouquet recebe em 1977 uma bolsa Fulbright para estudar o ensino da dança na Universidade de Columbia. Nos Estados Unidos, ela tem aulas com Irene Dowd e se forma na pratica somática Ideokinesis. De retorno à França, Odile Rouquet se dedica ao ensino do que chamou, inicialmente, de kinésiologie [cinesiologia], que em seguida é integrado pelo Ministério da Cultura como AFCMD. Criadora da associação Recherche em mouvement [Pesquisa em movimento] e autora de livros, artigos e documentários, Odile Rouquet deu aulas de AFCMD de 1989 a 2015 no Conservatório Nacional Superior de Música e Dança de Paris.
Hubert Godard ${ }^{4}$. Essas duas pessoas são os pilares fundadores deste campo de estudo na França, o qual chamo de forma sintética, mas problemática, "análise do movimento".

A terminologia suscitava problemas desde o início: tomemos como exemplo o trabalho de Odile Rouquet, que combina uma dupla trajetória - em dança e no que hoje é chamado de "educação somática". Nessa época, essas práticas eram chamadas de técnicas de release, de "novos métodos de consciência corporal5", ou ainda de "técnicas psico-corporais". Nas suas aulas, Odile transmitia os saberes da Ideokinesis de Irene Dowd misturados com outras práticas. Em 1985, Odile publicou um pequeno manual, Les techniques d'analyse du mouvement et le danseur ${ }^{6}$ [As técnicas de análise do movimento e o bailarino], no qual ela apresenta diferentes métodos de educação somática, dentre os quais estão o Body-Mind Centering (BMC), Feldenkrais, Alexander, etc. Como seu título indica, as "somáticas" eram categorizadas nessa época como "técnicas de análise do movimento". Eis aí um fato que pode ser uma referência histórica. Em seguida, o trabalho de Odile continuou a se desenvolver em uma estrutura mais institucional, dentro do Conservatório Nacional Superior de Música e

\footnotetext{
4 Formado inicialmente em Química, Hubert Godard é bailarino, pesquisador e professor. Suas pesquisas em análise do movimento foram desenvolvidas em múltiplas áreas: desde a década de 1980, ele estuda e ensina Rolfing (terapia criada pela americana Ida Rolf); participou da implementação do Diploma de Estado, coordenando com Odile Rouquet o ensino de AFCMD; foi professor e corresponsável do departamento de Dança da Universidade Paris 8 e, até hoje, faz pesquisas no Instituto Nacional do Câncer de Milão, na Itália.
}

5 ETEVENON, Pierre. "Préface" de: Rouquet, Odile. Les techniques d'analyse du mouvement et le danseur. Paris: FFD, 1985 , p. 3

6 ROUQUET, Odile. Les techniques d'analyse du mouvement et le danseur. Paris: FFD, 1985 (esgotado). Disponível online em: http://www.rechercheenmouvement.org/spip.php?article8. 
de Dança de Paris (CNSMDP).

É preciso ter em conta que a partir de 1989, para se tornar professor de dança na França, o bailarino era obrigado a possuir o Diplôme d'État (DE) [diploma de estado]. Hubert Godard conta o quanto foi preciso lutar para que a anatomia, a fisiologia e a análise funcional fossem ensinadas por bailarinos - formados, evidentemente - e não por médicos ou terapeutas. Uma vez que a AFCMD era uma matéria que fazia parte do exame de aptidão, os jovens que passavam pelas provas deveriam ser avaliados; foi necessário compor bancas examinadoras, profissionais formados por Odile ou por Hubert, então a formação se institucionalizou sob a forma de uma "formação de formadores". Esta continua até hoje, ainda sob a direção do Ministério da Cultura, que manteve essa denominação, AFCMD.

Por sua vez, Hubert Godard, que vinha do campo da dança e do teatro, também havia atravessado um grande número de "somáticas", para retomar a terminologia em vigor hoje em dia. Ele chefiava a formação em AFCMD e, na mesma época, aceita o convite de Michel Bernard - que tinha acabado de abrir, em 1989, o departamento de Dança da Paris 8 - e passa a dar aulas na universidade.

GH: Nós nos damos conta aqui da importância das práticas somáticas na construção do que é chamado "análise do movimento". Você poderia explicar como isso era trabalhado dentro das próprias aulas?

CR: Na verdade, no campo da dança contemporânea, já nesta época, muitos eram os bailarinos que seguiam outras práticas além de aulas técnicas de dança; essas práticas eram chamadas pelo nome de seus "criadores" (a técnica Alexander, o método Feldenkrais, o método Ehrenfried ${ }^{7}$, etc.). Depois, com o passar do tempo, alguns professores começaram a integrar as "somáticas" em suas investigações sobre a dança. O caso de Odile, através da Ideokinesis, mostra bem essa integração, essa espécie de cruzamento entre o gesto dançado, os exercícios de dança, a tomada de consciência pelo movimento, as interrogações sobre a pedagogia ${ }^{8} . .$. Essa mistura estava lá desde o princípio, as fronteiras sempre foram porosas, porque o que caracteriza essas técnicas é vir do campo da dança. Na França e no mundo, em todos os casos, esse campo é articulado diretamente ao campo da dança... Laban, Bartenieff, Irene Dowd, Bonnie Cohen, Odile Rouquet, Hubert Godard e todos seus alunos vêm principalmente deste campo. Existe um grande parentesco desde o início.

GH: E como você começou a trabalhar nesse campo?

CR: Completamente por acaso! Eu atravessei essas práticas ao longo de encontros, sem ter seguido integralmente uma formação "diplomante". Eu sempre pratiquei Feldenkrais, ginástica holística (que eu apreciava muito), Alexander, a anti-ginástica de Thérèse Bertherat e, em menor medida, BMC, um pouco de yoga... Isso fazia parte da minha vida, eu tinha a impressão que era como uma balança, existia a dança de um lado e essas práticas de outro; assim eu encontrava um equilíbrio.

Um problema que se coloca a cada um é a in-

7 Ou "ginástica holística". Cf. EHRENFRIED, Lily. La gymnastique holistique. De l'éducation du corps à celle de l'esprit. Paris: Aubier, 1956 [ed. bras.: Da educação do corpo ao equilíbrio do espirito. São Paulo: Summus, 1991]. Para uma bibliografia sobre "Somáticas e análise do movimento" ver: GINOT, Isabelle. Penser les somatiques avec Feldenkrais. Lavérune: L'Entretemps, 2014, p. 163-169.

8 Cf. documentário de Marie Hélène Rebois e Odile Rouquet, Le geste créateur. Paris: CNSMDP, 2008. 
tegração dessas práticas e de seus saberes no interior de um curso de dança. Quando eu fiz minhas primeiras aulas com Odile Rouquet, era uma época em que eu também dava aulas. Num dado momento, eu comecei a questionar tudo a tal ponto que as minhas aulas se transformavam cada vez mais e meus alunos acabaram dizendo: "Mas, espera lá, madame, já não são mais aulas de dança que você está dando". Então eu parei tudo, eu me dizia "efetivamente, isso não é o que os alunos esperam". Mesmo que nós fizéssemos sempre aulas práticas - e bem práticas - nos cursos de Odile ou de Hubert, nós não fazíamos ali uma aula de dança. Nós fazíamos muitas experimentações, muitas improvisações, leituras do gesto e da postura, etc., mas era mais da ordem de um atelier do que de uma aula técnica de dança. Nessa época, o parentesco entre dança e "somáticas" não estava integrado na aula técnica até onde sei, talvez apenas no trabalho de Peter Goss ${ }^{9}$. Enquanto que hoje isso é uma tentativa, talvez até mais do que uma tentativa. É, quem sabe, até mesmo o contrário: não há uma aula de dança que não tente integrar uma ótica somática em uma aula de técnica... E poucos pesquisadores se interessam pelos problemas que isso pode suscitar.

GH: Você poderia detalhar esse último ponto? CR: O principal problema diz respeito à modulação do tônus corporal. Muitas práticas somáticas baseiam seus trabalhos na postura deitada, em certa diminuição do tônus, na indução

9 O trabalho de Peter Goss (e de seus/suas assistentes) está no centro da formação de bailarinos contemporâneos, muitos fazem ou fizeram suas aulas em Paris ou em estágios. Peter Goss é professor também no CNSMDP. Cf. PRAUD, Dominique. "Danse contemporaine et pratiques somatiques: l'enseignement de Peter Goss". In: Incorporer, Nouvelles de danse, $n^{\circ}$ 46-47. Bruxelas: Contredanse, 2001, p. 188-197. Artigo disponível em: http://www.ecolepetergoss.com/docs/ texte d praud.pdf. de um estado de consciência modificado pelo relaxamento e pela lentidão. Trabalhamos os micromovimentos, bastante nutridos de imaginário, utilizamos a respiração abdominal, que é uma respiração de repouso e - do nada, youp! - é preciso se levantar e a aula precisa acontecer! A gente começa a fazer a memória funcionar e a se lembrar de coordenações motoras sendo que, até então, o cérebro estava mais em um estado de repouso. Quase sem nenhuma cerimônia, diretamente, temos que encontrar as coordenações e se engajar em um trabalho que envolve certo gasto de energia. Existe, aí, alguma coisa de uma ruptura: como lidar com ela? Até o momento, eu não vejo que a passagem de uma coisa a outra - do movimento muito lento ao movimento rápido e a um estado de tensão muscular - tenha sido questionada na teoria. Embora eu não duvide que em uma aula prática se possa, como o faz Peter Goss, articular com sabedoria a parte do trabalho no chão, lento, e as mudanças de nível no espaço, as modulações tônicas para conduzir ao movimento, mas nem todo mundo é Peter Goss... Eu percebo ainda que a maior parte das aulas de dança contemporânea atualmente começam com os alunos deitados no chão, o que para mim não deixa de ser uma questão...

GH: Sobre o seu percurso com Odile Rouquet, você diria que iniciou ali a construção de um conhecimento sobre o que você fazia na prática de dança? Que se abria desta forma a possibilidade de falar do que você estava fazendo? CR: Sim, mas sobretudo de descobrir aquilo que a gente fazia! Eu vou me lembrar para sempre do trabalho do demi-plié: aparentemente, um gesto "simples" - em uma aula técnica de dança, os demi-pliés fazem parte da barra do 
início da aula. Nessa época, com Odile, nós vivíamos experiências: experimentar um demi-plié nesse contexto revolucionava e alterava profundamente nossa maneira de pensar o aspecto mecânico do demi-plié na aula de técnica. Não era apenas perturbante, algumas vezes era mesmo desagradável.... Houve uma manhã em que eu não conseguia me levantar para ir à aula. Eu me dizia: "se toda vez eu tiver a impressão de que tenho que reaprender tudo e de que não sei mais nada, não é mais possível, eu vou acabar ficando louca". Na semana seguinte as coisas melhoraram e eu voltei ao curso, mas era complicado administrar as duas coisas ao mesmo tempo, a dança e a análise do movimento.

GH: O que você acha que uma prática de análise do movimento pode oferecer ao intérprete? Trata-se de uma abertura da percepção?

CR: Desde o início, a problemática de "o que isso traz ao intérprete" esteve presente. Há sempre uma tendência em dizer que é a questão pedagógica que está no cerne desse trabalho, e esta não é uma ideia equivocada. Mas estavam presentes, também desde o começo, as questões do trabalho do bailarino, da paleta de movimentos, da qualidade do gesto para a interpretação da escritura coreográfica. Nós passamos um número infinito de horas fazendo improvisações e assistindo juntos as improvisações dos outros, com Odile e depois com Hubert, na tentativa de nomear as qualidades do gesto, de um port de bras, por exemplo... A ideia, poderíamos dizer, é abrir a "paleta de coloridos" do intérprete - a cor sendo aquilo que sai do tubo de tinta, enquanto o colorido é aquilo que você inventa com as cores -, fazendo com que essa paleta se expanda, que possamos fazer escolhas a partir dela... Assim, você tem mais possibilidades de pintar o seu próprio quadro e de ser o autor do seu gesto.

GH: Estamos falando de uma abordagem teórico-prática. No seu percurso, o equilíbrio entre teoria e prática foi um problema em algum momento?

CR: Seria necessário fazer essa pergunta para outras colegas que, ao contrário de mim, dançaram muito profissionalmente. Eu imagino que a dificuldade que todos os bailarinos e praticantes das somáticas tiveram e ainda tem que atravessar é que em algum momento nós nos confrontamos com um vocabulário, uma gramática, uma sintaxe, em suma: com a escritura coreográfica de um determinado coreógrafo ou coreógrafa. E a eficiência estética não é da mesma ordem que pegar um objeto do chão sem ter dores nas costas. Refiro-me aqui ao que diz respeito à "danse d'école" a DOTE, a dança ocidental de tradição escrita, para retomar a terminologia dos músicos (que por sua vez utilizam o termo "MOTE"). Se você faz uma audição para dançar com Cunningham, com Forsythe ou com Preljocaj, você tem que confrontar qualquer coisa da imposição do gesto do outro, o que você aceita ou o que você não aceita. E se você não pode aceitar, o melhor então é não fazer a audição... Eu acho que a prática da análise do movimento pode nutrir a parte de autor que cada intérprete tem em si, mas o intérprete também pode nutrí-la de outra forma, é o que diz Boris Charmatz no livro escrito com Isabelle Launay ${ }^{10}$, isto é: através de atividades que nutrem nossa plasticidade perceptiva, através de experiências sensório-motoras que não são necessa-

10 CHARMATZ, Boris; LAUNAY, Isabelle. Entretenir, à propos de la danse contemporaine. Paris: CND, presses du réel, 2003. 
riamente da dança... Tudo isso nutre também a qualidade do meu gesto. Essas práticas "hors pistes" [off-road, fora de pista] vêm evidentemente enriquecer a prática técnica da dança. O que é difícil é ter distanciamento o suficiente para ver aonde elas vêm enriquecer, como elas vêm enriquecer e onde por ventura elas vêm impedir alguma coisa, tudo depende do contexto. A análise do movimento não é algo de positivo em si mesmo, não é uma "verdade" do gesto válida para todos! Na realidade, tudo depende de como cada intérprete, artista ou analista do movimento consegue questionar o contexto no qual ele inscreve sua experiência em um dado momento de sua história. Nem a análise do movimento, nem nenhuma prática somática, podem ser consideradas uma cura para todos os males! Pode ser que para algumas pessoas essas práticas possam ser percebidas como algo de tão perturbador que possam ter momentaneamente efeitos negativos, por que não? Você acha que seria evidente propor exercícios de lentidão e de propriocepção numa prática como o jazz, por exemplo?

GH: Nós poderíamos dizer que sob a categoria "análise do movimento" existem diferentes tipos de análise... A abordagem do departamento de Dança da Paris 8, por exemplo, não trabalha com a notação do movimento.

CR: Com o título do posfácio do livro sobre os Fattoumi-Lamoureux"11, "De l'analyse du mouvement" [Da análise do movimento], minha intenção era agrupar todo mundo em um mesmo nome. Pensei que, sob esta etiqueta, poderíamos reunir várias práticas, vários pensamentos. Eu também coloquei as aspas, porque, de acordo com o sentido atribuído a "análise"

11 ROQUET, Christine. "Postface". In: Fattoumi-Lamoureux, danser l'entre l'autre. Paris: Séguier, 2009, p. 166-171. ou a "movimento", isso não é algo óbvio; nós poderíamos então encontrar outras denominações, como "Leitura do gesto", "Abordagem qualitativa do gesto", "Leitura do movimento". Quando escolhemos as palavras, escolhemos certas ideias, e "análise do movimento" me pareceu suficientemente neutro para englobar todo mundo - ora, isso não é verdade, não é "neutro" como designação, mas esse é sempre o problema da categoria. A notação, por exemplo, é um sistema de transcrição e os notadores analisam movimentos. De nossa parte, nós não transcrevemos, nós não elaboramos partituras. É uma coisa que nos interessa, evidentemente, mas nós não somos notadores da dança, este é um outro ofício.

Uma maneira possível de sair da armadilha da designação é partir da proposição teórica de Michel Bernard, apresentada na Paris 8 em um encontro com estudantes. Michel dizia: por um lado, "descrever é perceber, identificar e designar". Existe toda uma parte de nosso campo no qual, efetivamente, alguém dança e nós observamos, nós percebemos o movimento (e eu não entrarei aqui na teoria bernardiana do sentir $^{12}$, fundamental para nós). Nós identificamos, uma identificação funcional, por exemplo, que consiste em observar as coordenações motoras e nós designamos, nós tentamos nomear, transcrever. Mas, acrescentava Michel Bernard: "analisar é buscar as condições de possibilidade do fenômeno"; em quais condições este fenômeno ocorre, se oferece à percepção, tanto para aquele que se movimenta quanto para aquele que assiste? $O$ trabalho de Hubert Godard ${ }^{13}$ na Paris 8 é exatamente

12 BERNARD, Michel. Sens et fiction, ou les effets étrangers des trois chiasmes sensoriels. In: Nouvelles de danse, $n^{\circ} 17$. Bruxelas: Contredanse, 1993, p. 56-64.

13 GODARD, Hubert. "Gesto e percepção". In: PEREIRA, R.; 
este, todas as nossas pesquisas sobre o pré-movimento, a atitude na postura, o questionamento constante da relação com o meio, a questão do sentido do gesto numa determinada situação, num dado momento, em tal ambiente... Isso é análise no sentido bernardiano do termo. O problema é que, a nível científico, "análise" não tem esse sentido. Em regra geral, analisar é cortar uma totalidade em subpartes cada vez menores, imaginando que ao utilizar o microscópio nós poderíamos ter uma visão da globalidade. Evidentemente, sabemos que isso não funciona para pensar o gesto, então, neste ponto, nós não fazemos uma "análise do movimento", não fazemos cortes em subsegmentos, não buscamos dividir um continuum em "unidades de movimento". Mas, segundo a teoria de Michel Bernard, fazemos análise do gesto. Tudo depende, então, do que se coloca sob o termo "análise".

Hoje em dia, o que me parece verdadeiramente interessante, é que cada um desenvolveu uma especificidade: em análise funcional [AFCMD], eles são super fortes na biomecânica, alguns são estudiosos do desenvolvimento da criança. A notação, por sua vez, exerce uma visão analítica propriamente dita, segundo modelos perfeitamente dominados ${ }^{14} \ldots$ Cada um desenvolve coisas que no final das contas são complementares. Seria necessário reinventar uma formação em análise do movimento que desse conta de todas essas camadas, que proponha tanto a transcrição do movimento - me parece indispensável que os bailarinos passem

SOTER, S. Lições de Dança 3. Tradução: Roberto Pereira. Rio de Janeiro: UniverCidade, 2002. A versão original em francês deste texto, assim como uma grande parte da bibliografia de Godard, está disponível online no site http://www.danse. univ-paris8.frl, na seção "Chercheurs et publications", "Les fondateurs".

14 Em Paris, o CNSMDP oferece uma formação em cinetografia (Laban) e uma formação em notação Benesh. por um sistema de notação e suas questões -, quanto uma formação em análise funcional que seria uma base técnica, e ainda considerar um olhar mais teórico, no sentido godardiano, onde nos questionamos sobre de onde e como pensamos, de onde e como olhamos, de onde e como construímos discursos sobre o gesto. Eu acredito que as coisas são complementares.

GH: Qual seria, então, a singularidade do trabaIho desenvolvido na Paris 8?

CR: O problema para mim de medir as distâncias em relação à $A F C M D$, é que a $A F C M D$ sem dúvida não é mais a mesma que eu vivenciei há trinta anos, eu penso que todo mundo avançou em seu caminho. O que me interessou, o que me fascinou, o que me fascina ainda e que talvez se distancie das práticas de AFCMD mais técnicas ou mesmo dos métodos de educação somática, é o questionamento incessante sobre o sentido do gesto. Embora seja importante saber ler um port de bras - como ele se organiza, qual é o motor do movimento, o que acontece na organização postural, em qual esquema respiratório, etc. -, se interessar também pelo sentido que pode ter esse gesto no final das contas, tanto para aquele que olha, quanto para aquele que o vive... O "sentido" não somente entendido como significado, mas como significância ${ }^{15}$, para retomar a proposição de Barthes sobre o "terceiro sentido". O sentido com seu lado indissociável de non-sens [não-sentido], do que escapa, do que não podemos necessariamente falar...

15 Cf. BARTHES, Roland. "Le troisième sens". In: Cahiers du cinéma, $\mathrm{n}^{\circ}$ 222, 1970 [ed. bras.: "O terceiro sentido". In: O óbvio e o obtuso: ensaios críticos III. Tradução: Léa Novaes. Rio de Janeiro: Nova Fronteira, 1990, p. 45-61]. 
GH: Isso implica às vezes uma postura crítica?

CR: Este é o segundo aspecto da especificidade do trabalho na Paris 8 . Há a questão do sentido que o distancia de várias práticas, mas há também a questão da perspectiva crítica e, portanto, da perspectiva autocrítica igualmente. Isto é, voltar a colocar sobre a mesa as suas próprias proposições e tentar pensar o impensável, ou seja, a partir de onde você pensa, como propõe filósofos como François Jullien ou Michel Bernard. É por isso que se dá grande importância para a problemática do uso do conceito de "corpo": ao utilizar certos conceitos, certas categorias, não necessariamente percebemos o impensado em que esta escolha é baseada (aqui, a dualidade irredutível entre "corpo" e "alma" ou "espírito"). $\mathrm{Na}$ proposição teórica de Godard, existe sempre a possibilidade de navegar em um sistema complexo; os elementos estão em interação. De vez em quando fazemos recortes - paramos em uma parte e utilizamos uma ferramenta, olhamos o que acontece -, mas logo em seguida tentamos pensar esse recorte que foi operado em interação dentro de um sistema vivo e dinâmico (o movimento sendo feito, o afeto atravessado por aquele que olha e por aquele que dança, a sensorialidade, etc.).

GH: É de alguma forma uma perspectiva filosófica?

CR: Sim, talvez. A dificuldade é que na prática é efetivamente uma fenomenologia, mas na teoria, é mais um pensamento do complexo ${ }^{16}$. Como se organizam as coisas? Como, explo-

16 Cf. MORIN, Edgard. Introduction à la pensée complexe. Paris: E.S.F., 1990 [ed. bras.: Introdução ao pensamento complexo. Porto Alegre: Sulina, 2006] e GUESPIN-MICHEL, Janine. Emancipation et pensée du complexe. Bellecombes-en-Bauges: Editions du Croquant, 2015. rando processos, dinâmicas entre o social, o cultural, a interação com aquele que olha, nós podemos elaborar hipóteses? Os alicerces teóricos do que fazemos na Paris 8 são em grande parte fundados por Michel Bernard ${ }^{17}$, particularmente suas teorias da alteridade, do imaginário, da corporeidade e do sentir. Além disso, nós somos fortemente inspirados pelo pensamento do processo, pelo trabalho de François Jullien, pela perspectiva atual de Tim Ingold na antropologia contemporânea...

GH: E como é que se explica que tenha sido na Universidade Paris 8 que essas questões surgiram?

CR: Em primeiro lugar, há o contexto dessa universidade, crítica por excelência, por assim dizer... Muitas coisas, ainda hoje, são possíveis nesta universidade precisamente e não são em outros lugares graças ao contexto histórico de Vincennes, da liberdade pedagógica, da liberdade de poder trabalhar as temáticas de pesquisa cruzando as disciplinas, do fato de poder abrir as formações a profissionais por equivalência, etc. Hubert aproveitou a oportunidade que lhe foi oferecida, mas era também um gesto político. Através de seu trabalho, ele podia dizer: "olhem, os bailarinos podem construir discursos sobre o que fazem, sobre o que eles veem; os bailarinos são fontes de saberes completamente interessantes e são capazes eles mesmos de colocar em palavras seus conhecimentos", para sair um pouco do silêncio... Essa era uma das questões que estavam na origem da construção desse departamento. $\mathrm{O}$ desejo de Michel Bernard era conferir à dança o status e a dimensão de pesquisa que ela merecia e que lhe faltava, em resumo. $\mathrm{Na}$

17 Principalmente em: BERNARD, Michel. De la création chorégraphique. Pantin: CND, 2001. 
música, isso existia, na pintura também e na dança isso não ocorria. Você tinha a impressão de que os bailarinos e as bailarinas deviam dançar, levantar a perna e ponto final.

\section{GH: E a abordagem desenvolvida hoje na Paris} 8 tem um nome?

CR: O nome sempre é um problema... Ainda mais que Hubert recusa-se a colocar um nome no que faz, pois ele sabe que nomear fixa as coisas, scripta manent. É uma questão importante no contexto universitário: se eu nomeio, se eu categorizo, eu fecho; "há definitivo na definição ${ }^{18 ",}$ diz Georges Didi-Huberman. Como deixar em aberto uma coisa quando a nomeamos? Eu acho que essa não é uma questão que precisa ser pensada anteriormente, é uma questão à qual devemos chegar. Na verdade, nosso foco é o gesto dançado e trata-se de experimentar, de observar e teorizar cada vez a partir de um ponto de vista e de mudar de perspectiva. Nós utilizamos várias ferramentas - a biomecânica, a filosofia, ferramentas da psicologia do desenvolvimento da criança, e ainda a psicanálise, as neurociências, etc. Essa abordagem, para não dizer "análise" (pois o termo leva à confusão), centrada no gesto, utiliza diversas ferramentas dependendo das questões que são colocadas, mas ela é também transdisciplinar na medida em que atravessa outros ensinamentos do departamento de Dança da Paris 8. Ela atravessa, por exemplo, a história da dança com Isabelle Launay, o campo da antropologia com Mahalia Lassibille. Nós tentamos sempre levar em conta o contexto, considerando o gesto como um sistema, um conjunto de múltiplos elementos em interação. É como quando Hubert fala da função tôni-

$\overline{18 \text { No original: "Il y }}$ a du définitif dans la définition". $\mathrm{ca}^{19}$ : ele fala de um sistema que compreende a postura ereta, as coordenações motoras, a percepção, a expressividade e de como todos esses elementos entram em interação em uma dada situação. De vez em quando, nós damos um zoom em um detalhe, observamos algo para validar ou não uma hipótese, ou para elaborar outra questão e, geralmente, levantamos mais questões do que oferecemos soluções! A teoria do pensamento complexo proporcionou a Godard - bailarino de formação cientifica, é preciso lembrar - ferramentas tais como a importância das condições iniciais, a noção de emergência, a da causalidade circular.... Essa teoria nos oferece conceitos que podem realmente ajudar a pensar o gesto no seu ambiente. Não devemos nem mesmo dizer "gesto", mas "gesto-no-seu-ambiente". Não existe uma causa única que conduz a um dado efeito, mas diferentes causas a este ou aquele fenômeno e, geralmente, ligações podem ser feitas sem que seja possível provar uma causalidade qualquer. $\mathrm{O}$ que definiria essa abordagem hoje em dia, é a complexidade. Se ela precisa ter um nome, na minha opinião, o que lhe faz justiça é "abordagem complexa do gesto expressivo", "expressivo" porque não é qualquer movimento e nos questionamos principalmente sobre a dança.

GH: Quais são os eixos de trabalho? Como você organiza suas aulas?

CR: Estamos em vários campos. Há o campo que já mencionamos, o campo da análise da interpretação em obras coreográficas. Nas

19 KUYPERS, Patricia. "Des trous noirs. Un entretien avec Hubert Godard". In: Scientifiquement danse, Nouvelles de danse, $n^{\circ}$ 53, Contredanse, 2006 [em português: "Buracos negros - uma entrevista com Hubert Godard". In: O Percevejo online, Dossiê Corpo Cênico, vol. 2, $n^{\circ}$ 2, Rio de Janeiro: PPGAC/UNIRIO, 2010, p. 1-21]. 
aulas, quando trabalhamos o olhar do espectador, trabalhamos a percepção justamente para mostrar aos estudantes como, percebendo de outro modo, ajustamos seu olhar sobre o movimento. Por exemplo, eu mostro um trecho de By myself ${ }^{20}$ com Fred Astaire e proponho em seguida uma pequena improvisação com óleos essenciais para tentar uma caminhada mais suspensa, mais aérea; e então nós assistimos de novo Fred Astaire para observar como esse ajuste da percepção muda o olhar sobre o gesto filmado.

Um outro campo é o da análise de práticas. Eu trabalhei com pedagogos da dança em minhas aulas. Por exemplo, nós fizemos um seminário de três anos chamado "colocação da bacia; da colocação ao movimento", no qual examinávamos quais eram as questões do trabalho de colocação da bacia no balé clássico, em Cunningham, em Graham e na dança oriental. Nosso interesse era examinar os aspectos de um gesto através de diversas práticas em um mesmo seminário.

GH: Você mencionou três eixos de trabalho, o que podemos chamar de "atelier do sentir", onde são trabalhadas as percepções do bailarino-analista; um segundo eixo seria a análise estética a partir do ponto de vista da interpretação do intérprete e, por último, a análise de práticas.

CR: Sim, e há também a análise de discursos.

GH: Sobre a análise de práticas, trata-se de trabalhar com a questão "qual corpo?" como formulou Laurence Louppe ${ }^{21}$ ?

20 "Solo" de abertura do filme A roda da fortuna de Vicente Minnelli (The band wagon, 1953), no qual Astaire percorre uma plataforma de trem cantando.

21 Principalmente em: LOUPPE, Laurence. Poétique de la
CR: A retórica que Laurence utiliza é por vezes mágica, há uma poética do discurso que é de alguém que era muito sensível à dança. Laurence trabalhou por um bom tempo com Hubert Godard e ela deu aulas no nosso departamento. Eu não acredito estar a traindo ao dizer que em seus livros, o que ela queria colocar não era tanto a questão "qual corpo", uma vez que trabalhando com esse conceito não conseguimos avançar. Não se trata de corpo "gordo", "magro", "negro", mas a questão de "qual gesto fabrica qual corpo?" que a interessa. Quando Laurence passa páginas a falar do fraseado, do peso, dos acentos, etc., ela fala do gesto. E é incrível, eu releio frequentemente Mauss, Hall e outros antropólogos que falam supostamente do corpo, e no final das contas eles não falam do corpo biológico, anatômico, eles falam do gesto. É esse o tema de Mauss em "As técnicas corporais"22". Tomemos como exemplo o nado, eu aprendi a nadar com os olhos abertos debaixo d'água ou com os olhos fechados? Aqui, nós estamos falando da percepção, que muda a coordenação completa do nado. Mauss não o nomeia assim, com essas palavras, mas ele está falando do gesto. A pergunta para Louppe seria, então, "qual gesto?" e não "qual corpo?".

GH: E me parece que não existem ferramentas dadas a priori, não?

CR: As ferramentas, a gente procura, a gente inventa, constrói quando estamos dentro da questão colocada pelo nosso olhar. De todo

danse contemporaine. Bruxelas: Contredanse, 1997 [ed. port.: Poética da dança contemporânea. Lisboa: Orfeu Negro, 2012].

22 MAUSS, Marcel. "Les techniques du corps". In: Sociologie et anthropologie [1936], Paris, PUF, 2001 [em português: "As Técnicas Corporais". In: Sociologia e Antropologia. São Paulo: Cosac Naify, 2003, p. 399-422]. 
modo, nós não temos uma caixa de ferramentas anteriores que preceda a questão, porque mesmo que se utilize as ferramentas do Effort de Laban, por exemplo - a riqueza das pesquisas sobre Laban vem do fato que seu sistema é também completamente aberto: espaço, tempo, peso e fluxo, você disse tudo e não disse nada (risos).

GH: Eu retomo uma frase presente no "Posfácio": "Experimentar e poder nomear aquilo que, no silêncio do gesto, se torna de alguma forma eloquente ${ }^{23}$ ", você poderia comentá-la?

CR: Aquilo que me chama a atenção sem que eu esteja necessariamente consciente disso... Essa é a dificuldade à qual me refiro quando falo do silêncio eloquente do gesto: existe alguma coisa que "fala comigo" quando estou em interação, quando estou vendo o gesto do outro... Existem coisas visíveis e evidentes, e há outras, que são menos - fenômenos que tentamos colocar em palavras com as teorias sobre os neurônios-espelho, a empatia, a sintonia afetiva (Daniel Stern), etc. Para isso, é necessário uma certa quantidade de ferramentas teóricas para observar o que acontece antes que um bailarino comece a se movimentar. Por exemplo, na minha última ida ao Rio, nós fomos assistir um espetáculo chamado Roots ${ }^{24}$, um duo magnífico, um trio poderíamos dizer, porque havia um músico [Pedro Bernardes] em cena. Roots é interpretado por dois bailarinos brasileiros da mesma geração. Ambos começaram suas carreiras na dança de rua quando

23 ROQUET, Christine. Fattoumi-Lamoureux, danser l'entre l'autre, op. cit., p. 168.

24 Roots, espetáculo apresentado pela primeira vez em julho de 2016 no Rio de Janeiro. A obra conta com dois bailarinos, Thiago Soares e Danilo d'Alma, e um músico, Pedro Bernardes, e foi dirigida por Renato Cruz e Ugo Alexandre. Christine fala de uma apresentação que aconteceu em janeiro de 2017 no Teatro Joao Caetano, Rio de Janeiro. eram pequenos; um deles continuou na dança de rua e hoje é mundialmente conhecido [Danilo d'Alma] e o outro seguiu uma formação de dança clássica no Rio e foi contratado pelo Royal Ballet de Londres [Thiago Soares]. Eles mal tinham entrado em cena, antes mesmo de fazer qualquer passo... e já era possível saber quem era quem! Era uma evidência! $\mathrm{Na}$ maneira de se colocar no espaço, na maneira de organizar o olhar, na maneira de respirar... Antes que eles se movessem, imediatamente sabíamos quem era quem. E não era uma questão de "qual corpo", mas a questão "quais gestos" e todo esse indizível que é carregado pela postura, pela variação da tonicidade, pela organização sensorial, pelo direcionamento do olhar no espaço, por como eles se preparavam para se deslocar em direção ao público... Antes mesmo de dançar. É isso que é eloquente. $E$ os bailarinos são especialistas em perceber isso. Depois, é claro, quando um deles faz um movimento de hip-hop e o outro faz três tours em l'air, você vê bem que um faz dança clássica e o outro hip-hop.

O que foi muito bonito nesse duo, é que após uma primeira parte "corporeidade clássica" eu mostro meu corpo, meu gesto acadêmico perfeito - com o cansaço, Thiago se senta e ali algo se solta e por trás do corpo clássico retorna o menino que fez dança de rua e, de repente, é uma coisa super interessante! Evidentemente, eu assisti esse espetáculo uma única vez, então eu não poderia dizer muito mais. Mas para uma antropóloga como Mahalia [Lassibille], teria sido incrível poder ler isso; porque existe alguma coisa da dança de rua que é o fundo tônico do bailarino, que estava presente por trás do gesto clássico. Na segunda parte, ele continua a fazer o gesto clássico, mas o gesto tem outra cor, outra dimensão. 
Eu não sei se é uma escolha do coreógrafo, se existem mesmo duas partes coreograficamente, se foi o cansaço que levou o intérprete até um limite, mas era uma coisa formidável de assistir. Este é o trabalho do intérprete: que isso possa ser conscientizado, que isso possa ser trabalhado.... Somente um bailarino pode fazer isso. Me parece importante fornecer ferramentas para que isso possa ser dito, porque senão esses saberes dos bailarinos permanecem desconhecidos para o mundo acadêmico e para o resto do mundo, na verdade.

Esse fundo da dança de rua que reaparecia sem aparecer na forma, na escritura, mas sim na coloração, nas dinâmicas, nas trocas com o outro... Não se trata de pensar que esta é uma verdade detida e que pode estar "fora do chão", que vou escrever um artigo sobre isso e que então eu teria dito tudo sobre o que aconteceu... Não. Foi muito interessante conversar com o coreógrafo depois do espetáculo, parece que ele não pôde trabalhar com o bailarino clássico todo o tempo, então ele trabalhou o papel com outro bailarino que vinha da dança de rua. Como as coisas são transmitidas? Depois, seria necessário fazer entrevistas com as pessoas, cruzar os olhares, analisar as práticas de ensaio e de construção, conversar também com o músico que criava a música ao mesmo tempo. Essa "abordagem complexa do gesto expressivo" é apenas uma perspectiva: olhamos alguma coisa e isso nos levanta questões. Isso não quer dizer que nós temos razão e que se exclui todo o resto, pelo contrário. No entanto, eu acho que se nós estamos sempre em outro lugar - isto é, se só fazemos entrevistas com os bailarinos, se nos interessamos apenas por suas trajetórias de vida, apenas pelas representações culturais, pela escritura coreográfica ou pela relação com a música -, esta- mos perdendo alguma coisa.

GH: Nas suas aulas, você repete frequentemente que para "analisar" é preciso que tenhamos um problema a resolver.

CR: Na verdade, o olhar sempre coloca uma questão, essa é a primeira dificuldade a entender. Não existe um olhar tautológico que se coloca da mesma maneira para cada um sobre um mero objeto, o olhar coloca uma questão. É claro, pode-se não questionar a questão, podemos dizer: "voilà, eu vou assistir este espetáculo e me contentar disso" e temos perfeitamente esse direito. Enquanto amadores de dança, temos o direito de só assistir ou então de só praticar a dança. Mas, se somos pesquisadores, pesquisadoras, e se tentamos produzir discursos sobre o que percebemos, hipóteses sobre o trabalho do bailarino e seu papel na sociedade, então temos de tentar fazer emergir a questão que é colocada pelo olhar, senão estamos apenas descrevendo - como vimos agora pouco com Michel Bernard: por exemplo, eu percebo uma música, eu a identifico como sendo a nona sinfonia de Beethoven, eu posso a nomear e a descrever, pelo menos o que está escrito na partitura. Mas o que isso diz da música? Quais questões sustentam o meu olhar e a minha escuta? É isso que Hubert quer dizer quando ele propõe a pergunta: "o que me emociona no gesto do outro?".

GH: Onde esse trabalho é desenvolvido hoje em dia?

CR: Se se trata de retomar exatamente o que Hubert faz na Paris 8, fora eu, diria "em lugar nenhum", mas isso não é verdade. Primeiro porque colegas da AFCMD atravessaram o 
departamento ${ }^{25}$ e também porque Hubert formou muitas pessoas em Rolfing e em AFCMD, profissionais que fizeram suas próprias misturas do que eles viveram com ele e com outras pessoas e que, à sua maneira, continuam então esse trabalho. No que me concerne, a continuação dessa pesquisa se faz com pesquisadores do Brasil principalmente, e não aqui na França. De vez em quando, me acontece de reencontrar bailarinos, coreógrafos e/ou estudantes que atravessaram nossas aulas e que pegaram algo, uma experiência, e desenvolveram uma coisa nova a partir disso, que seja uma escritura coreográfica, uma ferramenta teórica.... Você planta coisas sem muito saber. Mas em todo caso, ao nível de pesquisa, da instituição universitária e dos intercâmbios, isso acontece unicamente com o Brasil.

\section{GH: E como isso acontece?}

CR: De um modo completamente informal e muito improvisado (risos). Nós nos encontramos - e os pesquisadores e as pesquisadoras brasileiras se encontraram entre eles - em Porto Alegre, no Rio de Janeiro, em Salvador, em Fortaleza. Numa abordagem complexa (risos), a gente se cruza, atravessa coisas juntos e depois tentamos construir algo a partir disso. Agora chegamos em um estágio no qual nós vamos "institucionalizar" mais o grupo de pesquisa. Nós partimos na direção oposta ao que habitualmente acontece; geralmente você constrói uma rede internacional, você propõe então um projeto, tenta encontrar dinheiro e nutrir essas relações. Nós nos encontramos por acaso: eu fui para o encontro da ABRA$\mathrm{CE}^{26}$ em Porto Alegre em 2011, substituindo

25 Como por exemplo Dominique Praud, Emmanuelle Lyon, Romain Panassié.

26 Associação Brasileira de Pesquisa e Pós-Graduação em uma colega que não podia ir, e encontrei Suzi Weber, Mônica Dantas e outras pesquisadoras. Joana Ribeiro me convidou para ir à Unirio, ela editou um livro no qual eu publiquei um texto ${ }^{27}$, eu voltei para os colóquios, ateliers e as jornadas de estudo em Fortaleza, no Rio, em Salvador... E muitos colegas brasileiros e brasileiras vêm à Paris 8 . Até agora, nós mais experimentamos do que definimos e, talvez, mais experimentamos do que produzimos, mas nós chegamos à uma fase na qual devemos nos mostrar mais produtivos e mais construtivos, quero dizer, "academicamente" falando...

GH: Você também tem um projeto de publicação de um livro. Você poderia nos descrever esse trabalho?

CR: Esse livro é destinado a um público específico, o mundo da dança: bailarinos, coreógrafos, notadores, ensaiadores, etc., e àqueles que se interessam por isso - os amadores no sentido próprio do termo, aqueles que amam a dança, e não um livro universitário. A ideia é deixar um traço do que foi feito e pensado em análise do movimento no departamento de Dança da Paris 8 e poder oferecer também algumas ferramentas de leitura do gesto. Então, a ideia do livro é dar conta dos conhecimentos dos bailarinos, de saberes que passam pela prática e por uma língua especifica. Existem muitas locuções da dança - se apoiar no espaço, pegar a energia, dançar à escuta, etc. que não são um problema na dança, mas que

Artes Cênicas. Cf. ROQUET, Christine. "Ao encontro da criação: a análise do movimento e o processo de criação coreográfica". In: Da Cena Contemporânea. Porto Alegre: ABRACE, p. 39-45, 2012. Disponível em: http://portalabrace.org/ impressos/4 da cena contemporanea.pdf.

27 ROQUET, Christine. "Análise do movimento e análise de obras coreográficas”. In: KEISERMAN, Nara; TAVARES, Joana (org.). O corpo cênico: entre a dança e o teatro. São Paulo: Annablume, 2013, p. 249-255. 
do exterior podem parecer completamente estranhas. Essa língua da dança apoia-se em saberes próprios aos bailarinos, e eu gostaria de os esclarecer, tornando-os perceptíveis a todos que se interessam pelo assunto. Eu gostaria também de mostrar como - através de um corpus de imagens que estará em um DVD que acompanhará o livro - nós podemos aplicar os saberes da análise do movimento proveniente do campo da dança em obras coreográficas, pinturas, esculturas, etc. Esse livro vai se chamar Vu du geste: interpréter le mouvement dansé; "vu du geste » é, em francês falado, um jogo de palavras, é "vista" do gesto [sur] e "visto" a partir do gesto [depuis]. Eu tento sempre me situar ora do lado daquele que olha [espectador], ora do lado daquele que se move [intérprete].

GH: Qual é a importância de fazer essa pesquisa hoje?

CR: Nesse projeto editorial, o discurso é organizado em função das locuções da língua da dança, justamente para fazer emergir como os saberes dos bailarinos têm toda pertinência e devem ser expostos. Na minha opinião, isso parece eminentemente político no sentido que a dança está longe de ter atingido a dimensão de pesquisa, de ter sido levada a sério e de ter a validade acadêmica que ela teria o direito de receber. Muitas coisas mudaram em trinta anos, mas os estudos em dança na França continuam sendo o parente pobre das artes na universidade, isso é certo. Além disso, os bailarinos também fazem muitas coisas que têm uma dimensão política, naquilo que eu chamei anteriormente de práticas "hors piste", no que eles fazem com públicos à margem da sociedade, em hospitais, na prisão, em instituições especializadas, etc. A análise do movi- mento, a leitura do gesto, também está implicada nesses trabalhos, porque esses mesmos bailarinos misturam este conhecimento com os saberes provenientes da dança, das somáticas...

É verdade que a decisão de construir o departamento de Dança em 1989 foi um ato político forte da parte de Michel: dar à dança esse lugar na instituição universitária e, em seguida, oferecer a um profissional que não tinha doutorado [Hubert] a possibilidade de ser responsável pelo departamento, e no mesmo nível de um professor de filosofia! O departamento ${ }^{28}$ guarda alguma coisa disso no seu modo de funcionamento igualitário. Como diz Isabelle Ginot, há qualquer coisa de "vila gaulesa" no nosso departamento que não é unicamente esse oxigênio do gesto dançado, que nos une todos e todas de maneira subterrânea, mas que reside também nas escolhas políticas de funcionamento. E eu acho que um é indissociável do outro, há uma ligação entre o conteúdo e o funcionamento: trocar, fazer seminários comuns, o ensino em grupo, pensar nossas aulas coletivamente... Esses modos de funcionamento institucionais não são separáveis do fato que compartilhamos uma mesma visão dos estudos em dança, uma espécie de acordo subterrâneo, uma atitude de pesquisa. Eu diria, então, que a "abordagem complexa do gesto expressivo" não é uma disciplina, é uma movência, é profundamente uma atitude de pesquisa que pode ser partilhada por todos os colegas, mesmo que estes não tenham necessariamente ferramentas precisas de biomecânica, por exemplo. Trata-se de uma aborda-

28 Para uma introdução ao trabalho desenvolvido no departamento de Dança da Universidade Paris 8, cf. GINOT, Isabelle et al. "Le Département Danse de l'université Paris 8 Vincennes Saint Denis: quelques repères". In: Recherches en danse [online], $\mathrm{n}^{\circ}$ 1, 2014, URL: http://danse.revues.org/644. 
gem transdisciplinar, no sentido que atravessa os campos de pesquisa tanto de um quanto de outro. E é bom assim.

Recebido em 15/04/2017

Aprovado em 19/06/2017 